\title{
Komparasi Hasil Terjemahan Google Translate dan Bing Translator dalam Menerjemahkan Hedging Words
}

\author{
Laila Nur Aflah \\ Magister Linguistics, Faculty of Cultural Sciences, \\ Universitas Gadjah Mada, Yogyakarta, Indonesia \\ Email: layla.sastro@gmail.com
}

\begin{tabular}{l} 
Article Info \\
\hline Article history: \\
Submitted Dec 19, 2019 \\
Revised Jan 17, 2020 \\
Accepted March 26, 2020 \\
Published April 30, 2020 \\
\hline
\end{tabular}

\section{Keywords:}

Bing Translator Google Translate Hedging Words Studi Komparasi Terjemahan

\begin{abstract}
This study aims to explain the comparison of the translation results of two translation machines, Google Translate and Bing Translator. The object of this research is the hedging words contained in one of the opinions in The Jakarta Post's online newspaper entitled Why Indonesians should write about Indonesia in English more often. The types of hedges that appear in the article and become the object of research are in four types, namely: lexical verb, modal auxiliary verb, compound hedges, and adverb of frequency. From the analysis conducted, the writer found that the translation of hedging words with two translation machines assisted different results of the translation are identical. The method used by the two translation machines is literal translation so that the form and meaning of the source text is equivalent to the form and meaning of the target text. The author believes that the artificial intelligence developed in those two translation machines has different abilities and can be proven by research with wider and more varied sentence objects.
\end{abstract}

Corresponding Author:

Laila Nur Aflah

Universitas Gadjah Mada, Yogyakarta, Indonesia

Bulaksumur, Caturtunggal, Kec. Depok, Kabupaten Sleman, Yogyakarta 55281

Email: layla.sastro@gmail.com

\section{PENDAHULUAN}

Kegiatan dan kebutuhan penerjemahan merupakan salah satu hal yang terus dibutuhkan dari zaman ke zaman. Putrawan mengatakan bahwa penerjemahan memiliki peran yang sangat penting dalam berbagai bidang termasuk dalam bidang keilmuan, komunikasi, bisnis, pariwisata, agama, dan lain sebagainya (2017: 11) dan teknologi turut menyokong dan terlibat dalam kegiatan ini. Perkembangan teknologi pada abad ke 21 ini sangat masif, termasuk perkembangannya dalam mengembangkan mesin bebantuan terjemahan. Penciptaan mesin terjemahan ini membuat kegiatan terjemahan menjadi lebih mudah, hal inilah yang kemudian membuat mesin terjemahan disebut dengan mesin terjemahan otomatis. Adapun mesin terjemahan yang terhubung dengan internet sangatlah banyak, baik yang berbayar maupun tidak seperti Google Translate, ProZ, Translator Café, dan lain sebagainya (Putrawan, 2017: 15). Adapun masing-masing dari mesin terjemahan tersebut memiliki kelebihan dan kekurangan masing-masing.

Salah satu mesin terjemahan yang paling terkenal dan paling mudah diakses adalah Google Translate (Precup-Stiegelbauer, 2013: 1). Seseorang yang menggunakan mesin GT ini dapat dengan mudah menerjemahkan sebuah dokumen dari satu bahasa ke bahasa lain. selain itu, Kardimin juga mengatakan bahwa GT merupakan mesin terjemahan 
yang paling banyak penggunanya di dunia ini (2013: 269). Secara umum, diketahui bahwa GT merupakan mesin terjemahan berbasis SMT atau statistical machine translation, dimana input data yang dimasukkan oleh penggunanya akan dikenali pola kalimatnya secara statis dan diterjemahkan berdasarkan pola yang dikenali dan kesesuaian pola antara bahasa target dan bahasa sumber. Pola yang dimaksud tentunya adalah pola statis tata bahasa yang dikenali oleh GT. Adapun pola yang baru diinputkan oleh pengguna, akan masuk ke dalam memori mesin yang menjadi saran perkembangan bagi kemajuan dan validitas mesin terjemahan tersebut mendatang. Disisi lain, Ayuwuragil (CNN Indonesia: t.t.) mengatakan bahwa sejak 2017, GT mengembangkan sistem NMT dalam penerjemahannya, neural machine translation ini merupakan salah satu kecerdasan buatan yang diaplikasikan pada mesin penerjemah yang diharapkan dapat membuat GT lebih cerdas sehingga hasil terjemahan yang dihasilkan akan lebih akurat.

Selain GT, terdapat mesin terjemahan yang dikeluarkan oleh perusahaan terkenal, Microsoft, yaitu Microsoft translator. Namun dalam penggunaannya mesin ini terintegrasi dengan berbagai konsumen dan developer sehingga memiliki nama dan penyebutan yang berbeda bagi tiap produknya. Adapun salah satu produk dari Microsoft yang bekerja dalam bidang penerjemahan adalah Bing Translator. BT ini memiliki fitur yang hampir sama dengan Google Translate, ia dapat menerjemahkan kata, kalimat, paragraph, hingga sebuah tulisan utuh dalam waktu sepersekian detik. Seperti GT, input yang dapat dimasukkan dalam alat ini dapat berupa teks, live speech atau conversation, text to speech, dan image. Kesamaan yang lain adalah bahwa Bing Translator ini juga memiliki sistem Neural, atau NMT ("Microsoft Translator Languages - Microsoft Translator," 2019) dan memiliki batas input 5000 kata per sekali penggunaan. Selain itu aplikasi ini juga hanya membutuhkan koneksi internet untuk penggunaannya dan tidak berbayar.

Dengan banyaknya kesamaan pada kedua mesin terjemahan otomatis tersebut, apakah hasil terjemahan yang akan dihasilkan juga akan sama atau sebaliknya. Dari sini penulis akan menguji hasil terjemahan kedua mesin ini dengan memasukkan input berupa hedging words. Holmes (2008: 299) mengatakan bahwa fitur linguistik ini (hedges) berfungsi untuk mengungkapkan sebuah ketidakpercaya diri seseorang dalam berbicara ataupun untuk memperlihatkan sebuah ekspresi kurang yakin ataupun tentative. Adapun fungsi lain dari hedges atau hedging adalah untuk menunjukkan sebuah kesopanan, menghindari face-threat lawan bicara, dan sebagainya (Rosanti \& Jaelani, 2016: 31). Adapun hedging memiliki klasifikasi bentuk yang sangat beragam, yaitu: modal auxiliary verb (will, must, might, can, should, etc), lexical verb (appear, believe, assume, suggest, etc), probability adjective noun (possible, likely, certain, etc), adverb (practically, probably, perhaps, etc.), adverb of frequency (often, sometimes, etc.), if-clause (if true, if . . . etc.), compound hedges (may be suggested, seems reasonable, etc.), and fillers (you know, you see, well, umm, etc.). Masing-masing jenis dari hedges akan memiliki arti yang berbeda jika diterjemahkan ke dalam bahasa lain, hal ini sangat bergantung pada konteks kalimat secara utuh. Hal ini menjadikan analisa tentang hedges tidak hanya dapat dilakukan kata per kata saja, namun juga mempertimbangkan konteks dari kalimat yang disertai oleh hedges tersebut.

Sebelumnya, penelitian tentang hedges dalam kaitannya dengan proses terjemahan telah dilakukan oleh Axelsson (2013: 2) yang membahas tentang terjemahan hedges dari bahasa Inggris ke dalam bahasa Swedia. Ia mengambil objek dari buku akademik bidang sains yang memuat hedges. Ia menemukan bahwa penggunaan hedges terbanyak dalam buku tersebut adalah dalam bentuk adverb dan auxiliary. Dari keseluruhan hedges yang ditemukan, hampir seluruh hedges diterjemahkan secara literal kata demi kata dengan tujuan untuk mempertahankan gaya stilistik dari teks akademik itu sendiri. Namun demikian, banyak terjadi penghilangan dan penyesuaian dilakukan untuk mempertahankan makna teks sumber ketika diterjemahkan ke dalam bahasa sasaran. 
Axelsson menyarankan adanya keterlibatan teknik sense for sense dalam penerjemahan teks ini.

Dari uraian diatas, penelitian tentang terjemahan hedging words dari bahasa Inggris ke dalam bahasa Indonesia ini menjadi penting untuk dilakukan untuk mengetahui metode dan tipe terjemahan apa yang dipakai oleh dua mesin bebantuan terjemahan yang berbeda (Google Translate dan Bing Translator) dimana keduanya merupakan aplikasi mesin terjemahan dari dua perusahaan terkenal, yang memiliki fitur hampir sama dan juga tidak berbayar. Selain itu penelitian ini juga dilakukan untuk menjawab apakah ada kesamaan bentuk dalam penggunaan hedges antara bahasa Indonesia dan bahasa Inggris. Penelitian ini diharapkan mampu menjelaskan permasalahan tersebut secara mendetail.

\section{TEORI DAN METODOLOGI}

Penelitian ini bertujuan untuk mengetahui perbedaan hasil terjemahan antara dua mesin bebantuan terjemah, yaitu Google Translate dan Bing Translator dalam menerjemahkan hedging words. Adapun hedging words yang dijadikan objek dalam penelitian ini adalah kata-kata hedging yang terdapat dalam sebuah artikel opini dalam surat kabar online The Jakarta Post. Adapun pemilihan judul opini yang diteliti dipilih berdasarkan ketersediaan hedging words dalam satu redaksi opini utuh. Penulis memilih bacaan yang memuat paling tidak sepuluh hedging words dalam satu tulisan utuh untuk dijadikan objek penelitian, adapun isi dari opini dalam berita tersebut tidak menjadi hal yang penting dan masuk dalam konsiderasi pemilihan judul bacaan untuk dijadikan objek kajian penelitian. Penulis juga memilih artikel dari sebuah surat kabar ternama The Jakarta Post, karena koran tersebut merupakan koran yang memiliki kredibilitas bahasa yang baik dalam dunia jurnalistik Indonesia sehingga tata bahasa yang dipaparkan sesuai dengan kaidah bahasa Inggris.

Temuan dari hedging words dalam surat kabar berbahasa Inggris tersebut kemudian diterjemahkan dengan menggunakan dua mesin bebantuan terjemahan yang berbeda yaitu Google Translate dan Bing Translator. Klasifikasi kata-kata hedging dan analisis pada masing-masing terjemahan kemudian dilakukan untuk mendapatkan sebuah kesimpulan penelitian. Meskipun data dalam penelitian ini dapat dikatakan minim, namun penulis percaya bahwa analisi yang dilakukan dapat dijadikan representasi hasil terjemahan dari dua mesin bebantuan terjemahan yang berbeda.

Adapun teori yang digunakan dalam penelitian ini adalah teori terjemahan dimana menerjemah menurut Catford (1978: 20) adalah pemindahan materi tekstual dari sebuah bahasa ke dalam bahasa lain secara ekuivalen. Word for word dan literal translation menjadi dua jenis tipe yang kemungkinan besar mendekati sistem terjemahan mesin bebantuan penerjemah. Word for word translation adalah mengalihbahasakan teks sumber ke dalam bahasa sasaran namun seringkali terjemahan dengan tipe ini membuat hasil terjemahan menjadi aneh karena makna dan konteks dari kalimat bukan sebagai fokus utama dari penerjemahan tipe ini. Sedangkan literal translation menurut Larson (1998: 17) adalah mentrasnfer bentuk dari SL ke dalam bentuk TL.

Dalam melakukan analisis data, penulis membandingkan hasil terjemahan dari Google Translate dan Bing Translator berdasarkan klasifikasi hedging words dan kesesuaian arti kata-kata tersebut dengan konteksnya. Dimana hedging words sendiri memiliki klasifikasi makna dan tujuan penggunaan yang bermacam-macam. Keberagaman macam makna dan fungsi dari objek kajian tersebutlah yang akan memunculkan arti yang berbeda-beda dalam penggunaan dengan konteks kalimat yang berbeda pula.

\section{HASIL DAN PEMBAHASAN}

Dari data hedges yang diambil dari koran online The Jakarta Post dengan judul bacaan Why Indonesians should write about Indonesia in English more often (Post, 25 Juni 2019), 
kemudian diterjemahkan menggunakan dua mesin bebantuan terjemahan yang berbeda, berikut adalah pemaparan terjemahan tersebut:

\begin{tabular}{|c|c|c|c|c|}
\hline No. & Teks Sumber & Google Translate & Bing Translator & Klasifikasi \\
\hline 1 & $\begin{array}{l}\text { She found Indonesia } \\
\text { really intriguing } \\
\text { and described it as } \\
\text { a "bad boyfriend", } \\
\text { which seems to be } \\
\text { an affectionate term } \\
\text { but it implies how } \\
\text { strange, illogical } \\
\text { and exotic } \\
\text { Indonesians are. }\end{array}$ & $\begin{array}{l}\text { Dia menemukan } \\
\text { Indonesia benar-benar } \\
\text { menarik dan } \\
\text { menggambarkannya } \\
\text { sebagai "pacar yang } \\
\text { buruk", yang } \\
\text { tampaknya merupakan } \\
\text { istilah yang penuh kasih } \\
\text { sayang tetapi itu } \\
\text { menyiratkan betapa } \\
\text { anehnya, orang } \\
\text { Indonesia yang aneh, } \\
\text { tidak logis dan eksotis. }\end{array}$ & $\begin{array}{l}\text { Dia menemukan } \\
\text { Indonesia sangat menarik } \\
\text { dan menggambarkannya } \\
\text { sebagai "pacar yang } \\
\text { buruk", yang tampaknya } \\
\text { menjadi istilah yang } \\
\text { penuh kasih sayang tetapi } \\
\text { menyiratkan betapa aneh, } \\
\text { tidak logis dan eksotis } \\
\text { Indonesia. }\end{array}$ & Lexical verb \\
\hline 2 & $\begin{array}{l}\text { People may have } \\
\text { different views on } \\
\text { Indonesia, but such } \\
\text { a depiction can } \\
\text { affect the image of } \\
\text { our country in the } \\
\text { eyes of many } \\
\text { people. }\end{array}$ & $\begin{array}{l}\text { Orang mungkin } \\
\text { memiliki pandangan } \\
\text { yang berbeda tentang } \\
\text { Indonesia, tetapi } \\
\text { penggambaran seperti } \\
\text { itu dapat memengaruhi } \\
\text { citra negara kita di mata } \\
\text { banyak orang. }\end{array}$ & $\begin{array}{l}\text { Orang mungkin memiliki } \\
\text { pandangan yang berbeda } \\
\text { di Indonesia, tetapi } \\
\text { seperti penggambaran } \\
\text { dapat mempengaruhi } \\
\text { citra negara kita di mata } \\
\text { banyak orang. }\end{array}$ & $\begin{array}{l}\text { Modal } \\
\text { auxiliary verb }\end{array}$ \\
\hline 3 & $\begin{array}{l}\text { I believe that } \\
\text { teachers don't allow } \\
\text { students to use } \\
\text { Indonesian terms } \\
\text { because they want } \\
\text { us to practice } \\
\text { English, but they } \\
\text { cannot "ban" us } \\
\text { from doing so when } \\
\text { we have clearly } \\
\text { explained the } \\
\text { meaning of the } \\
\text { phrases. }\end{array}$ & $\begin{array}{l}\text { Saya percaya bahwa } \\
\text { guru tidak mengizinkan } \\
\text { siswa untuk } \\
\text { menggunakan istilah } \\
\text { bahasa Indonesia karena } \\
\text { mereka ingin kita } \\
\text { berlatih bahasa Inggris, } \\
\text { tetapi mereka tidak } \\
\text { dapat "melarang" kita } \\
\text { untuk melakukannya } \\
\text { ketika kita telah dengan } \\
\text { jelas menjelaskan arti } \\
\text { dari frasa tersebut. }\end{array}$ & $\begin{array}{l}\text { Saya percaya bahwa } \\
\text { guru tidak mengijinkan } \\
\text { siswa untuk } \\
\text { menggunakan istilah } \\
\text { Indonesia karena mereka } \\
\text { ingin kita untuk } \\
\text { mempraktekkan bahasa } \\
\text { Inggris, tetapi mereka } \\
\text { tidak dapat "melarang" } \\
\text { kita dari melakukannya } \\
\text { ketika kita telah jelas } \\
\text { menjelaskan arti dari } \\
\text { frase. }\end{array}$ & Lexical verb \\
\hline 4 & $\begin{array}{l}\text { We can express our } \\
\text { concern on } \\
\text { Indonesia through } \\
\text { writing in another } \\
\text { language. }\end{array}$ & $\begin{array}{l}\text { Kami dapat } \\
\text { mengungkapkan } \\
\text { keprihatinan kami pada } \\
\text { Indonesia melalui } \\
\text { tulisan dalam bahasa } \\
\text { lain. }\end{array}$ & $\begin{array}{l}\text { Kita dapat } \\
\text { mengungkapkan } \\
\text { kepedulian kita terhadap } \\
\text { Indonesia melalui } \\
\text { penulisan dalam bahasa } \\
\text { lain. }\end{array}$ & $\begin{array}{l}\text { Modal } \\
\text { auxiliary verb }\end{array}$ \\
\hline 5 & $\begin{array}{l}\text { In Pramoedya } \\
\text { Ananta Toer's } \\
\text { book, Panggil Aku } \\
\text { Kartini Saja (Just } \\
\text { Call Me Kartini), she } \\
\text { elaborated her view } \\
\text { on gamelan, } \\
\text { "Gamelan never } \\
\text { cheers; even in } \\
\text { exuberant parties, } \\
\text { we can still hear the }\end{array}$ & $\begin{array}{l}\text { Dalam buku Pramoedya } \\
\text { Ananta Toer, Panggil } \\
\text { Aku Kartini Saja, ia } \\
\text { menguraikan } \\
\text { pandangannya tentang } \\
\text { gamelan, "Gamelan tidak } \\
\text { pernah bersorak; } \\
\text { bahkan di pesta yang } \\
\text { penuh kegembiraan, kita } \\
\text { masih bisa mendengar } \\
\text { suara serius gamelan; }\end{array}$ & $\begin{array}{l}\text { Dalam buku Pramoedya } \\
\text { Ananta Toer, Panggil aku } \\
\text { Kartini saja (Just call me } \\
\text { Kartini), ia menguraikan } \\
\text { pandangan tentang } \\
\text { gamelan, "gamelan tidak } \\
\text { pernah sorak-sorai; } \\
\text { bahkan dalam pesta yang } \\
\text { meriah, kita masih bisa } \\
\text { mendengarkan suara } \\
\text { gamelan yang khidmat; }\end{array}$ & $\begin{array}{l}\text { Modal } \\
\text { auxiliary verb } \\
\text { - lexical verb- } \\
\text { lexical verb }\end{array}$ \\
\hline
\end{tabular}




\begin{tabular}{|c|c|c|c|c|}
\hline & $\begin{array}{l}\text { gamelan's solemn } \\
\text { voice; maybe it's } \\
\text { supposed to be like } \\
\text { that. Life is a } \\
\text { solemn voice, not a } \\
\text { cheerful choir." }\end{array}$ & $\begin{array}{l}\text { mungkin seharusnya } \\
\text { seperti itu. Hidup adalah } \\
\text { suara yang khusyuk, } \\
\text { bukan paduan suara } \\
\text { yang ceria." }\end{array}$ & $\begin{array}{l}\text { mungkin itu } \\
\text { seharusnya menjadi } \\
\text { seperti itu. Hidup adalah } \\
\text { suara khusyuk, bukan } \\
\text { paduan suara yang ceria. } \\
\text { " }\end{array}$ & \\
\hline 6 & $\begin{array}{l}\text { This suggests that } \\
\text { Kartini was worried } \\
\text { that education } \\
\text { without arts would } \\
\text { dismiss the teaching } \\
\text { of character. }\end{array}$ & $\begin{array}{l}\text { Ini menunjukkan } \\
\text { bahwa Kartini khawatir } \\
\text { bahwa pendidikan tanpa } \\
\text { seni akan mengabaikan } \\
\text { pengajaran karakter. }\end{array}$ & $\begin{array}{l}\text { Hal ini menunjukkan } \\
\text { bahwa Kartini khawatir } \\
\text { bahwa pendidikan tanpa } \\
\text { seni akan } \\
\text { memberhentikan } \\
\text { pengajaran karakter. }\end{array}$ & Lexical verb \\
\hline 7 & $\begin{array}{l}\text { Schools seem to } \\
\text { rarely introduce to } \\
\text { their students } \\
\text { Indonesian } \\
\text { literature or books } \\
\text { discussing } \\
\text { Indonesian history } \\
\text { and culture. }\end{array}$ & $\begin{array}{l}\text { Sekolah-sekolah } \\
\text { tampaknya jarang } \\
\text { memperkenalkan } \\
\text { kepada siswa-siswa } \\
\text { mereka literatur atau } \\
\text { buku-buku Indonesia } \\
\text { yang membahas sejarah } \\
\text { dan budaya Indonesia. }\end{array}$ & $\begin{array}{l}\text { Sekolah tampaknya } \\
\text { jarang memperkenalkan } \\
\text { kepada siswanya sastra } \\
\text { Indonesia atau buku yang } \\
\text { membahas sejarah dan } \\
\text { budaya Indonesia. }\end{array}$ & Lexical verb \\
\hline 8 & $\begin{array}{l}\text { He suggested us to } \\
\text { read his books as he } \\
\text { said the plots are } \\
\text { interesting and that } \\
\text { it could help us } \\
\text { understand how } \\
\text { people of our } \\
\text { country lived in the } \\
\text { past. }\end{array}$ & $\begin{array}{l}\text { Dia menyarankan kita } \\
\text { untuk membaca buku- } \\
\text { bukunya karena dia } \\
\text { mengatakan plot itu } \\
\text { menarik dan itu bisa } \\
\text { membantu kita } \\
\text { memahami bagaimana } \\
\text { orang-orang di negara } \\
\text { kita hidup di masa lalu. }\end{array}$ & $\begin{array}{l}\text { Dia menyarankan kami } \\
\text { untuk membaca buku- } \\
\text { bukunya seperti yang dia } \\
\text { katakan plot yang } \\
\text { menarik dan bahwa hal } \\
\text { itu bisa membantu kita } \\
\text { memahami bagaimana } \\
\text { orang dari negara kita } \\
\text { tinggal di masa lalu. }\end{array}$ & Lexical verb \\
\hline 9 & $\begin{array}{l}\text { My teacher also } \\
\text { often helps us } \\
\text { practice our writing } \\
\text { skills while using } \\
\text { materials about } \\
\text { Indonesia's history } \\
\text { or culture. }\end{array}$ & $\begin{array}{l}\text { Guru saya juga sering } \\
\text { membantu kami melatih } \\
\text { keterampilan menulis } \\
\text { sambil menggunakan } \\
\text { materi tentang sejarah } \\
\text { atau budaya Indonesia. }\end{array}$ & $\begin{array}{l}\text { Guru saya juga sering } \\
\text { membantu kami } \\
\text { mempraktikkan } \\
\text { keterampilan menulis } \\
\text { kami sambil } \\
\text { menggunakan materi } \\
\text { tentang sejarah atau } \\
\text { budaya Indonesia. }\end{array}$ & $\begin{array}{l}\text { Adverb of } \\
\text { frequency }\end{array}$ \\
\hline 10 & $\begin{array}{l}\text { We should be able } \\
\text { to talk about our } \\
\text { experience as } \\
\text { Indonesians as } \\
\text { what Kartini had } \\
\text { done. }\end{array}$ & $\begin{array}{l}\text { Kita harus bisa } \\
\text { berbicara tentang } \\
\text { pengalaman kita sebagai } \\
\text { orang Indonesia seperti } \\
\text { apa yang telah dilakukan } \\
\text { Kartini. }\end{array}$ & $\begin{array}{l}\text { Kita harus mampu } \\
\text { membicarakan } \\
\text { pengalaman kita sebagai } \\
\text { orang Indonesia seperti } \\
\text { yang telah dilakukan } \\
\text { Kartini. }\end{array}$ & $\begin{array}{l}\text { Modal } \\
\text { auxiliary verb }\end{array}$ \\
\hline 11 & $\begin{array}{l}\text { By incorporating a } \\
\text { drip of our culture } \\
\text { in our writings, we } \\
\text { can provide anyone } \\
\text { who reads it a taste. }\end{array}$ & $\begin{array}{l}\text { Dengan memasukkan } \\
\text { tetesan budaya kita ke } \\
\text { dalam tulisan kita, kita } \\
\text { dapat memberikan } \\
\text { siapa pun yang } \\
\text { membacanya } \\
\text { merasakan. }\end{array}$ & $\begin{array}{l}\text { Dengan memasukkan } \\
\text { tetesan budaya kita } \\
\text { dalam tulisan kita, kita } \\
\text { dapat menyediakan siapa } \\
\text { saja yang membacanya } \\
\text { rasa. }\end{array}$ & $\begin{array}{l}\text { Modal } \\
\text { auxiliary verb }\end{array}$ \\
\hline 12 & $\begin{array}{l}\text { This could then } \\
\text { initiate a cycle } \\
\text { where more and } \\
\text { more people will } \\
\text { start writing using } \\
\text { our unique }\end{array}$ & $\begin{array}{l}\text { Ini kemudian dapat } \\
\text { memulai siklus di mana } \\
\text { semakin banyak orang } \\
\text { akan mulai menulis } \\
\text { menggunakan tradisi } \\
\text { unik kita, di mana }\end{array}$ & $\begin{array}{l}\text { Hal ini kemudian dapat } \\
\text { memulai sebuah siklus di } \\
\text { mana semakin banyak } \\
\text { orang akan mulai menulis } \\
\text { dengan menggunakan } \\
\text { tradisi kami yang unik, di }\end{array}$ & $\begin{array}{l}\text { Modal } \\
\text { auxiliary verb }\end{array}$ \\
\hline
\end{tabular}




\begin{tabular}{|l|l|l|l|l|}
\hline traditions, where & semakin banyak buku & mana kemudian lebih dan & \\
then more and & tentang Indonesia dapat & lebih banyak buku \\
more books about & diterbitkan, sehingga & tentang Indonesia dapat & \\
Indonesia can be & semakin banyak orang & dipublikasikan, sehingga & \\
published, so more & dapat belajar tentang & semakin banyak orang & \\
and more people & sejarah dan budaya kita & dapat belajar tentang & \\
can learn about our & yang hebat. & sejarah dan budaya yang & \\
great history and & & besar. & \\
culture. & & & \\
\hline
\end{tabular}

Dari tabel diatas, dapat dilihat bahwa hedges muncul dalam 12 kalimat dari keseluruhan teks opini yang diambil. Adapun klasifikasinya adalah sebagai berikut:

\begin{tabular}{|c|c|}
\hline Lexical ver & \\
\hline Seems & : GT = 'tampaknya' \\
\hline & $\mathrm{BT}=$ 'tampaknya" \\
\hline Believe & : GT = 'percaya' \\
\hline & BT $=$ 'percaya' \\
\hline Maybe & : $\mathrm{GT}=$ mungkin" \\
\hline & $\mathrm{BT}=$ 'mungkin' \\
\hline Supposed & : GT = 'seharusnya' \\
\hline & BT = 'seharusnya' \\
\hline Suggest (1) & : GT = "menunjukkan" \\
\hline & $\mathrm{BT}=$ 'menunjukkan' \\
\hline Suggest (2) & : GT = 'menyarankan' \\
\hline & BT $=$ 'menyarankan' \\
\hline
\end{tabular}

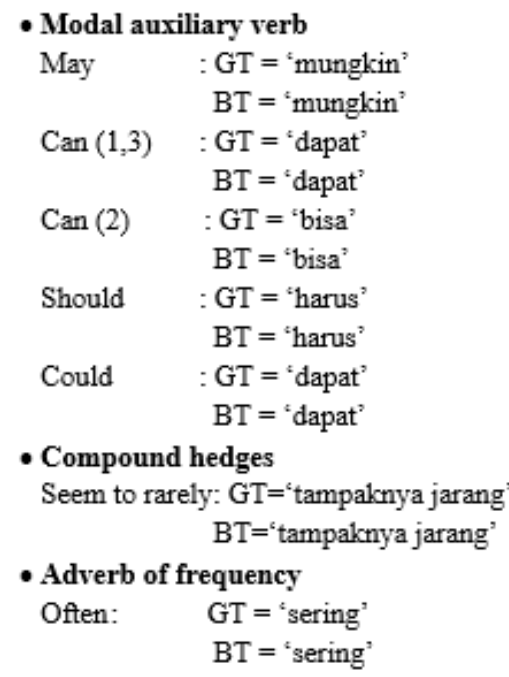

Ada empat tipe dari hedges yang dipakai dalam opini surat kabar online The Jakarta Post berjudul Why Indonesians should write about Indonesia in English more often. Yang pertama adalah lexical verb yang memiliki jumlah enam kali kemunculan. Kemunculan pertama pada paragraph pertama kalimat kedua berupa hedging word 'seem'. Dalam terjemahannya menggunakan Google Translate dan Bing Translator, kata seem diartikan dengan 'tampaknya'. Dalam ekuivalensi terjemahan kedua mesin terjemahan tersebut memberikan makna TL yang sama pada kata seem dan kata-kata selain itu, yaitu: believe, maybe, dan suppose. Kata believe diartikan dengan 'percaya', kata maybe diartikan dengan 'mungkin', dan kata suppose diartikan dengan 'seharusnya'. Keempat kata tersebut secara makna dapat diterima dalam bahasa sasaran. Namun begitu dalam penggunaan lexical verb dalam opini tersebut terdapat satu kata dengan dua kali kemunculan dan diartikan dalam istilah bahasa sasaran yang berbeda, yaitu kata suggest. Dalam kemuculan pertamanya suggest diartikan dengan 'menunjukkan' dengan konteks kalimat This suggests that Kartini was worried that education without arts would dismiss the teaching of character sedangkan pada kemunculan keduanya diartikan dengan 'menyarankan' yaitu pada kalimat He suggested us to read his books as he said the plots are interesting and that it could help us understand how people of our country lived in the past. Kedua arti tersebut secara literal sudah berterima dengan konteks kalimat ketika diubah kedalam TL.

Adapun tipe hedging words selanjutnya yang muncul dan banyak digunakan dalam artikel opini tersebut adalah tipe modal auxiliary verbs. Ada enam kali kemunculan dengan 3 kemunculan berbentuk sama yaitu kata can muncul dalam tiga kalimat yang berbeda dan memunculkan dua arti. Pada kemunculan pertama dan ketiga, kata can diartikan dengan kata 'dapat', dan pada kemunculan kedua nya diartikan dengan kata 
'bisa'. Adapun maksud dari kata 'dapat' dan 'bisa' adalah sejenis namun beda dari segi keformalan pemakaiannya. Can ini juga muncul satu kali dalam bentuk lampau yaitu could yang diartikan oleh mesin dengan kata 'dapat'. Selain kata can, kemunculan hedges tipe modal auxiliary verb hanya muncul satu kali, yaitu: may yang diartikan dengan kata 'mungkin' dan should yang diartikan dengan kata 'harus'. Secara umum, keseluruhan modal auxiliary verb yang diartikan dengan menggunakan GT ataupun BT tidak memunculkan arti yang berbeda, kedua mesin tersebut menerjemahkan kata-kata tersebut dengan kata yang sama.

Tipe hedges ketiga yang muncul adalah compound hedges, tipe ini hanya muncul satu kali dalam satu artikel opini utuh yang dipilih oleh penulis, yaitu kata seem to rarely dalam kalimat Schools seem to rarely introduce to their students Indonesian literature or books discussing Indonesian history and culture. Dalam terjemahan GT dan BT sama-sama menerjemahkan kalimat majemuk tersebut dengan kata 'tampaknya jarang'. Adapun secara makna, terjemahan tersebut telah sesuai dan berterima dalam bahasa sasaran.

Adverb of frequency sebagai salah satu tipe hedges yang muncul dalam artikel opini tersebut juga muncul satu kali, yaitu dengan kata often. Kedua mesin bebantuan terjemahan tersebut mengartikan kata often dengan kata 'sering'. Dalam konteks kalimat My teacher also often helps us practice our writing skills while using materials about Indonesia's history or culture, kata 'sering' pada kalimat 'Guru saya juga sering membantu kami ...' merupakan terjemahan yang ekuivalen dan berterima dalam bahasa sasaran.

Meskipun jika dilihat dari uraian diatas, secara kata per kata hedges yang diteliti tidak memunculkan perbedaan diantara dua mesin bebantuan terjemahan yang berbeda, namun penulis percaya bahwa kedua mesin tersebut tidaklah sama secara keseluruhan. Hal tersebut dapat dibuktikan selanjutnya dengan penelitian mendalam dengan data bahasa dan input teks yang lebih beragam.

\section{SIMPULAN}

Dari uraian diatas, penulis dapat menyimpulkan bahwa dalam menerjemahkan hedging words dari data yang diambil dari sebuah artikel opini The Jakarta Post dengan judul Why Indonesians should write about Indonesia in English more often tidak ada perbedaan antara hasil terjemahan Google Translate dan Bing Translator. Dari segi akurasi dan ekuivalensi, keduanya juga menyajikan hasil terjemahan yang akurat dan berterima dalam bahasa sasaran. Hal ini membuat keduanya menjadi salah dua mesin bebantuan terjemahan tidak berbayar yang direkomendasikan untuk digunakan dalam membantu pekerjaan menerjemahkan.

Namun begitu, kedua mesin bebantuan terjemahan tersebut bukanlah mesin dengan kecerdasan yang sama persis sehingga dengan penelitian lain penulis percaya akan ditemukannya perbedaan dalam hasil penerjemahannya. Adapun hedges yang muncul dalam artikel ini terdiri dari empat tipe yaitu lexical verb dan modal auxiliary verb dengan jumlah kemunculan terbanyak yaitu 6 kali kemunculan. Kemudian tipe compound hedges dan adverb of frequency dengan kemunculan masing-masing satu kali dalam satu artikel utuh opini yang disajikan.

\section{REFERENSI}

Axelsson, L. (2013). Translating Hedges: a study of the translation of hedges from English to Swedish in an academic text.

Ayuwuragil, K. (t.t.). Teknologi NMT bikin google translate makin akurat. Diambil 18 Juni 2019, dari teknologi website: https://www.cnnindonesia.com/teknologi/20170427170031-185-

210704/teknologi-nmt-bikin-google-translate-makin-akurat 
Catford, J. C. (1978). A linguistik theory of translation: An essay in applied linguistiks (5th impr). Dalam Language and Language Learning: Vol. 8 (5th impr). Oxford: Oxford Univ. Press.

Holmes, J. (2008). An introduction to sociolinguistiks. Pearson Longman.

Kardimin. (2013). Pintar Menerjemah: Wawasan Teoritik dan Praktek. Yogyakarta: Pustaka Pelajar.

Larson, M. L. (1998). Meaning-based translation: A guide to cross-language equivalence (2nd ed). Lanham, Md: University Press of America.

Microsoft Translator Languages - Microsoft Translator. (t.t.). Diambil 24 Juni 2019, dari Microsoft Translator for Consumers website: https://www.microsoft.com/enus/translator/languages/

Post, T. J. (t.t.). Why Indonesians should write about Indonesia in English more often. Diambil 21 Juni 2019, dari The Jakarta Post website: https://www.thejakartapost.com/youth/2016/07/18/why-indonesians-shouldwrite-about-indonesia-in-english-more-often.html

Precup-Stiegelbauer, L.-R. (2013). Automatic translations versus human translations in nowadays world. Procedia - Social and Behavioral Sciences, 70, 1768-1777. https://doi.org/10.1016/j.sbspro.2013.01.252

Putrawan, G. E. (2017). Basic understanding of translation (theoretical and practical points of view). Yogyakarta: Garha Ilmu.

Rosanti, E. D., \& Jaelani, A. (2016). The use of lexical hedges in spoken language by female and male students. ENGLISH JOURNAL, 16(1), 29-39. 